\title{
Sexual quality of life in Hodgkin Lymphoma: a longitudinal analysis by the German Hodgkin Study Group
}

K Behringer ${ }^{1}$, H Müller ${ }^{1}$, H Görgen ${ }^{1}$, H-H Flechtner ${ }^{2}$, C Brillant ${ }^{1}$, T V Halbsguth ${ }^{1}$, I Thielen ${ }^{1}$, D A Eichenauer ${ }^{1}$, $\mathrm{T} \mathrm{Schober}^{1}, \mathrm{H}$ Nisters-Backes ${ }^{1}, \mathrm{M} \mathrm{Fuchs}^{1}$, A Engert ${ }^{1}$ and $\mathrm{P}$ Borchmann ${ }^{*}, 1$ on behalf of the German Hodgkin Study Group

${ }^{1}$ First Department of Internal Medicine, German Hodgkin Study Group (GHSG), University of Cologne, Kerpener Street 62, D-50924 Cologne, Germany and ${ }^{2}$ Department of Psychiatry for Children and Adolescents, University of Magdeburg, Magdeburg, Germany

Background: Health-related quality of life (HROoL) comprises different domains of physical, mental, and social well-being. In this analysis, we focus on sexual quality of life in Hodgkin Lymphoma $(\mathrm{HL})$ patients.

Methods: Four-thousand one-hundred and sixty patients enroled in the HD10-HD12 trials underwent HRQoL assessment. Instruments included the Quality of Life Questionnaire for survivors (QLQ-S), combining the European Organisation for Research and Treatment of Cancer QLQ-C30, Multidimensional fatigue (FA) inventory (MFI-20) and an additional sexual functioning (SX) scale. We describe SX up to 27 months after therapy and analyse relationship to stage, age, gender, FA, social functioning, and therapy. Statistical methods range from descriptive statistics to a classification of SX courses, and a longitudinal structural equations model with full information maximum likelihood estimation of missing data. In the analysis, a score below 50 was used to describe severe sexual dysfunction.

Results: Three-thousand two-hundred and eight patients provided data on SX. Patients in advanced stages reported lower SX than patients in early stages both, before and after the treatment. During follow-up, an improvement of SX compared with baseline was detected, except for those $\geqslant 50$ years. Patients in early stages reached normal SX, whereas advanced-stage patients remained below the reference value for healthy controls. Sexual functioning during follow-up was significantly and strongly related to previous SX, other HRQoL measures, age, and stage, and to lesser degree with gender and chemotherapy.

Conclusion: Overall, HL patients have a decreased sexual quality of life at baseline, which improves after therapy and normalises in early-stage patients. Importantly, long-term SX is more closely related to patient characteristics and SX at baseline than to the intensity of treatment.

Cancer and cancer treatment have a negative impact on sexual functioning (SX). There are physical, as well as psychological causes of sexual dysfunction and sexual problems vary depending on prediagnosis function, patient response, and specific treatment
(Mercadante et al, 2010; Sadovsky et al, 2010). A full discussion of the anticipated gonadal toxicity and sexual problems is required in each patient. It should be started before treatment and continued during the follow-up period (Schover, 2005; Quinn et al, 2007;

*Correspondence: Prof. Dr P Borchmann;

E-mail: peter.borchmann@uni-koeln.de

Results were in part presented at 51st ASH Annual Meeting and

Exposition, New Orleans, LA, 2009.

Received 11 June 2012; revised 8 November 2012; accepted 19 November 2012

(c) 2013 Cancer Research UK. All rights reserved 0007-0920/13 
Zebrack et al, 2007; Park et al, 2009). However, sexual health is often not addressed by the treating physician (Fegg et al, 2003; Bober et al, 2009; Park et al, 2009; Mercadante et al, 2010), emphasising the need for specialized training in survivorship care (Bober et al, 2009).

Sexual quality of life has to address at least three points: First, the rate of therapy-induced infertility and hypogonadism. Second, fertility preservation techniques. Third, the psychological aspect of sexuality, such as changes in sexual desire, social relationships, and their impact on quality of life.

Although data on infertility rates after lymphoma treatment have been published (Franchi-Rezgui et al, 2003; Behringer et al, 2005; van der Kaaij et al, 2007; De Bruin et al, 2008; Sieniawski et al, 2008), only little is known on sexual function before, during and after therapy. Long-term sexual dysfunction has been documented in patients with solid tumours (Schover 2005; Webber et al, 2011). In contrast, only few data are available for SX in lymphoma survivors and most of them are limited to the follow-up period (Kornblith et al, 1992a; Kornblith et al, 1992b; Abrahamsen et al, 1998; Heutte et al, 2009; Kiserud et al, 2009; Recklitis et al, 2010). In our analysis, having information on SX and patients characteristics already before starting treatment allows an investigation of possible correlations between these characteristics and SX independently of Hodgkin Lymphoma (HL) therapy. To shed some light on sexual problems in lymphoma patients, we investigated SX of $3208 \mathrm{HL}$ patients from diagnosis up to 27 months later. Survivors of all stages will be described and relationships with clinical stage (CS), age, and gender, as well as other quality of life dimensions will be explored. Additionally, a longitudinal model will be proposed. The long-term courses of SX are classified using pre- and post-therapy functioning to complete the detailed quantitative analysis with some clinically useful categories.

\section{PATIENTS AND METHODS}

Patient selection. From 1998 to 2002, the German Hodgkin Study Group (GHSG) conducted the 4th generation of clinical trials for the treatment of HL (HD10-12) involving a total of 4610 patients. Patients between 16 and 75 years (except HD12 trial: not older than 65 years) had to have biopsy-proven HL at diagnosis to be eligible for randomisation. Eligibility criteria included adequate organ function as published elsewhere (Engert et al, 2009). The studies were performed in accordance with the declaration of Helsinki and the International Conference on Harmonisation guidelines for Good Clinical Practice. We report on all patients who provided information on their SX up to 27 months after therapy. The present analysis is based on the data status of March 2010 .

Study design (HD10-HD12). In the HD10 study for early stages (CS I, II without risk factors) patients were randomized to receive 2 or 4 cycles of doxorubicin, bleomycin, vinblastine, and dacarbazine (ABVD) followed by either $30 \mathrm{~Gy}$ or $20 \mathrm{~Gy}$ involved-field (IF) radiotherapy (Engert et al, 2010). Stage I or II patients with risk factors and stage IIB patients with elevated erythrocyte sedimentation rate and/or involvement of $>2$ lymph node areas were enroled into the HD11 trial (Eich et al, 2010). Treatment consisted of four cycles ABVD or four cycles of baseline bleomycin, etoposide, doxorubicin, cyclophosphamide, vincristine, procarbazine, and prednisone (BEACOPP), followed by 30 Gy or 20 Gy IF RT. The HD12 trial included patients in CS IIB with risk factors, as well as all CS III and IV patients. Eight cycles of escalated BEACOPP were compared with four cycles of escalated BEACOPP followed by four cycles of BEACOPP baseline (' $4+4$ '). Patients were randomly assigned to receive additional RT on initial bulk or residual disease or no RT (Borchmann et al, 2011).

Assessment of Health-related quality of life. Patients completed the Quality of Life Questionnaire for survivors (QLQ-S) and the life situation questionnaire at the time of diagnosis, after chemotherapy (CT), after RT, and at follow-up examinations. The QLQ-S was developed and validated together with the EORTC (European Organisation for Research and Treatment of Cancer) and is composed of the EORTC QLQ-C30, the MFI-20, an additional scale for SX and some specific items (Flechtner et al, 1998). The EORTC QLQ-C30 questionnaire incorporates five functioning scales (physical, role, cognitive, emotional, and social), three symptom scales (fatigue (FA), pain, nausea, and vomiting), and a global health and quality of life scale. Questions refer to the health status and have a graded response format ranging from $1=$ 'not at all' to $4=$ 'very much (with exception for the sevenpoint scale for global quality of life). All raw scores are linearly transformed to 0 to 100 scales. Higher scores represent a better level of functioning for the five functional scales, whereas the symptom scales and items are scaled in the opposite direction (Aaronson et al, 1993). In all scales and items an absolute difference of $>10$ points is a commonly accepted criterion for clinically relevant differences (Osoba et al, 1998, 2005; Cocks et al, 2008). The SX scale (three items) with established psychometric properties was derived from the Health-related quality of life (HRQoL) studies of the German Testicular Cancer Trial Group. The scale was designed according to the EORTC Quality of Life Group requirements, used the same format and scoring algorithm as the regular QLQ-C30 scales, and was validated in two large longitudinal multicentre trials in individuals who had survived testicular cancer (Aaronson et al, 1993; Flechtner et al, 1998; Weissbach et al, 2000; Heutte et al, 2009). Questions of the scale refer to changes in sexual interest, sexual activity, and satisfaction. Written informed consent of all participants is confirmed.

Statistics. Descriptive statistics with means and 95\% confidence intervals were used to describe courses of SX. Beginning with measurements before therapy (B), after CT, and after RT, the follow-up period is described up to 27 months after diagnosis (F). Follow-up data were assigned to 3-monthly intervals starting from 9 months after diagnosis - if therapy was finished -, up to 27 months. Sexual functioning courses are given for the three studies and stages, randomized treatment groups, and predefined subgroups of sex, age $(\geqslant 50$ years $), F A(F A \geqslant 50)$ and social functions $(\mathrm{SFs}<50)$ at baseline. These cutoffs for FA and SF were chosen to reflect severe HRQoL deficits which often demand clinical interventions. (Cocks et al, 2008).

Structural equation modelling (SEM) was used to describe relations between HRQoL domains and to estimate a longitudinal Markov model for the variables analysed in the descriptive part. We employed Mplus 5.21 to perform these multivariate analyses and used its full information maximum likelihood technique to account for missing data (Muthén and Muthén, 1998-2007). To reduce the complexity of these analyses, we limited the time resolution of the SEM model to three points in time: baseline, after therapy (12 to 18 months) and at 2 year follow-up (18 to 27 months). The model was estimated in multiple group analyses of the three stages and the above-defined subgroups of sex and age. The level of significance for subgroup comparisons was set to $P<01$ without any corrections for multiple testing.

Classification of SX courses. As there are no established threshold levels for the evaluation of specific QoL dimensions, we choose a 50-point cutoff for the discrimination between patients with or without SX impairment as this value is proposed as threshold level for clinical interventions (Klinkhammer-Schalke et al, 2008). By choosing this cutoff point, we refer to serious impairments of SX. 
A cutoff score of 50 was used to classify longitudinal SX patterns individually: for all time points, SX below 50 was judged as SX deficit. With respect to the time before, during, and after therapy the following seven course types resulted (Table 1).

Reference scores. Data from a previous study on the psychometric properties of our questionnaire in 927 healthy subjects yielded the following means of SX as reference scores: 78.5 for the general population, 83.3 for men $(n=425)$ and 74.5 for women $(n=502)$, 82.5 for people younger than 50 years $(n=762)$, and 60.0 for people older than 50 years $(n=165)$ (Ruffer et al, 2003). These means served as reference lines in the respective figures to support interpretation.

\section{RESULTS}

Patient characteristics. A total of 4160 patients qualified for the present analysis. Of the entire sample, 952 did not respond to the

Table 1. Definition of course patterns depending on the presence of SX deficits before, during and after treatment

\begin{tabular}{|l|c|c|c|}
\hline Category description & Before & During & After \\
\hline Never & $\mathrm{N}$ & $\mathrm{N}$ & $\mathrm{N}$ \\
\hline Temporary & $\mathrm{N}$ & $\mathrm{Y}$ & $\mathrm{N}$ \\
\hline Therapy related & $\mathrm{N}$ & $\star$ & $\mathrm{Y}$ \\
\hline Continuously & $\mathrm{Y}$ & $*$ & $\mathrm{Y}$ \\
\hline Unspecified long-term deficit & Missing & $*$ & $\mathrm{Y}$ \\
\hline Cured & $\mathrm{Y}$ & $*$ & $\mathrm{~N}$ \\
\hline Fluctuating & $*$ & $*$ & Mix of $\mathrm{Y}$ and N \\
\hline Abbreviations: SX = sexual functioning; $\mathrm{Y}=\mathrm{yes} ; \mathrm{N}=\mathrm{no} ;{ }^{*}=$ not relevant. \\
\hline
\end{tabular}

items on SX, thus, 3208 patients $(77.1 \%)$ provided data for the longitudinal SX courses (Figure 1, Consort). Table 2 describes the patient characteristics and lists them separately for patients with and without SX data. At diagnosis, patients included in our QoL analyses had slightly less disease burden than patients without SX data. Moreover, patients included were slightly younger.

Sexual functioning courses and HL stage. There were clear differences between SX scores of patients in different stages before therapy. Baseline scores for early unfavourable or advanced-stage patients were $<10$ points lower compared with the healthy control population (reference line). Lowest SX scores were observed after

Consort chart

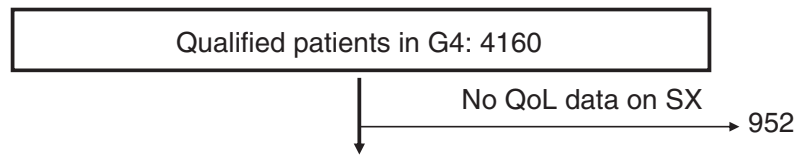

\begin{tabular}{|c|c|c|c|c|c|}
\hline \multicolumn{6}{|c|}{ QoL sample: 3208 (77.1\%) } \\
\hline & $N$ & $\%$ & & $N$ & $\%$ \\
\hline Baseline: & 2771 & $86.4 \%$ & Therapy: & 2244 & $70.0 \%$ \\
\hline Follow-up 1: & 856 & $26.7 \%$ & Follow-up 4: & : 609 & $19.0 \%$ \\
\hline Follow-up 2: & 743 & $23.2 \%$ & Follow-up 5: & 556 & $17.3 \%$ \\
\hline Follow-up 3: & 675 & $21.0 \%$ & Follow-up 6: & : 408 & $12.7 \%$ \\
\hline & seline, $t$ & $\begin{array}{r}\text { At leas } \\
\text { therapy a }\end{array}$ & $\begin{array}{l}\text { st } 1 \text { follow-up: } \\
\text { and follow-up: }\end{array}$ & $\begin{array}{l}1799 \\
: 1247\end{array}$ & $\begin{array}{l}56.1 \% \\
38.9 \%\end{array}$ \\
\hline${ }^{\text {\#Relative fre }}$ & equenc & yin QoL & sample & & \\
\hline
\end{tabular}

HD10: $922(77.5 \%) \quad$ HD11:1101 (78.9\%) HD12:1185 (75.5\%)

Figure 1. Consort chart of recruited and analysed patient numbers.

Table 2. Patient characteristics

\begin{tabular}{|c|c|c|c|c|c|c|c|c|}
\hline Variable & Statistic & $\begin{array}{c}\text { Total } \\
\mathbf{N}=4160\end{array}$ & $\begin{array}{l}\text { Without SX data } \\
\qquad N=952\end{array}$ & $\begin{array}{l}\text { With SX data } \\
\qquad \mathbf{N}=3208\end{array}$ & $P^{\star}$ & $\begin{array}{l}\text { HD10 } \\
\mathbf{N}=922\end{array}$ & $\begin{array}{l}\text { With SX data HD11 } \\
\qquad \mathbf{N}=1101\end{array}$ & $\begin{array}{c}\text { HD12 } \\
\mathbf{N}=1185\end{array}$ \\
\hline Age & $\begin{array}{l}\text { Years, } \\
\text { mean } \pm \text { s.d. }\end{array}$ & $36.4 \pm 13.6$ & $37.8 \pm 14.4$ & $36.0 \pm 13.3$ & 0.0016 & $38.5 \pm 14.0$ & $34.9 \pm 13.3$ & $35.0 \pm 12.4$ \\
\hline Sex & Female, $N(\%)$ & $1788(43.0)$ & $406(42.6)$ & $1382(43.1)$ & 0.82 & $357(38.7)$ & $567(51.5)$ & $458(38.6)$ \\
\hline $\begin{array}{l}\text { Ann Arbour stage } \\
\text { IA } \\
\text { IB } \\
\text { IIA } \\
\text { IIB } \\
\text { IIIA } \\
\text { IIIB } \\
\text { IVA } \\
\text { IVB }\end{array}$ & $\begin{array}{l}N(\%) \\
N(\%) \\
N(\%) \\
N(\%) \\
N(\%) \\
N(\%) \\
N(\%) \\
N(\%)\end{array}$ & $\begin{array}{c}404(9.7) \\
61(1.5) \\
1647(40.2) \\
687(16.5) \\
352(8.5) \\
425(10.2) \\
151(3.6) \\
403(9.7)\end{array}$ & $\begin{array}{c}88(9.2) \\
14(1.5) \\
367(38.6) \\
126(13.2) \\
75(7.9) \\
111(11.7) \\
40(4.2) \\
130(13.7)\end{array}$ & $\begin{array}{c}316(9.9) \\
47(1.5) \\
1307(40.7) \\
561(17.5) \\
277(8.6) \\
314(9.8) \\
111(3.5) \\
273(8.5)\end{array}$ & $<0.0001$ & $\begin{aligned} 283 & (30.7) \\
18 & (2.0) \\
565 & (61.3) \\
55 & (6.0) \\
& - \\
& - \\
& - \\
& -\end{aligned}$ & $\begin{array}{c}33(3.0) \\
29(2.6) \\
741(67.3) \\
298(27.1) \\
- \\
- \\
- \\
-\end{array}$ & $\begin{array}{c}- \\
- \\
1(0.1) \\
208(17.6) \\
277(23.4) \\
314(26.5) \\
111(9.4) \\
273(23.0)\end{array}$ \\
\hline Mediastinal mass & $N(\%)$ & $719(33.4)$ & $173(18.2)$ & $546(17.0)$ & 0.41 & - & 201 (18.3) & $345(29.1)$ \\
\hline Extranodal Involvement & $N(\%)$ & $471(11.3)$ & $136(14.3)$ & 335 (10.4) & 0.0011 & - & $101(9.2)$ & 234 (19.7) \\
\hline$>3$ Nodal areas & $N(\%)$ & 2257 (54.3) & $527(55.4)$ & $1730(53.9)$ & 0.44 & - & 753 (68.4) & $977(82.4)$ \\
\hline High ESR & $N(\%)$ & $1772(42.6)$ & $421(44.2)$ & 1351 (42.1) & 0.12 & - & $573(52.0)$ & $778(65.7)$ \\
\hline Partner & Single, $N(\% v)$ & NA & NA & 1158 (42.0) & NA & $309(39.8)$ & $388(41.2)$ & $461(44.2)$ \\
\hline Children & Yes, $N(\% v)$ & NA & NA & $1428(51.7)$ & NA & $426(54.9)$ & $460(48.8)$ & $542(52.0)$ \\
\hline Employment & Yes, $N(\% v)$ & NA & NA & $1996(72.7)$ & NA & $569(73.4)$ & $660(70.4)$ & 767 (74.1) \\
\hline Smoking & Yes, $N(\% v)$ & NA & NA & 1015 (37.2) & NA & 301 (39.2) & $323(34.7)$ & 391 (37.9) \\
\hline
\end{tabular}


CT. In early stages, SX improved after RT and reached normal level. In advanced stages, SX also improved during follow-up beyond the baseline values but remained below the reference line (Figure 2A).

Types of SX courses according to HL stage. Half of all patients analysed (50.1\%) never reported severe impairment of SX (category 1). Symptom-free patients were more common in early favourable stages and less common in advanced stages. A similar pattern was
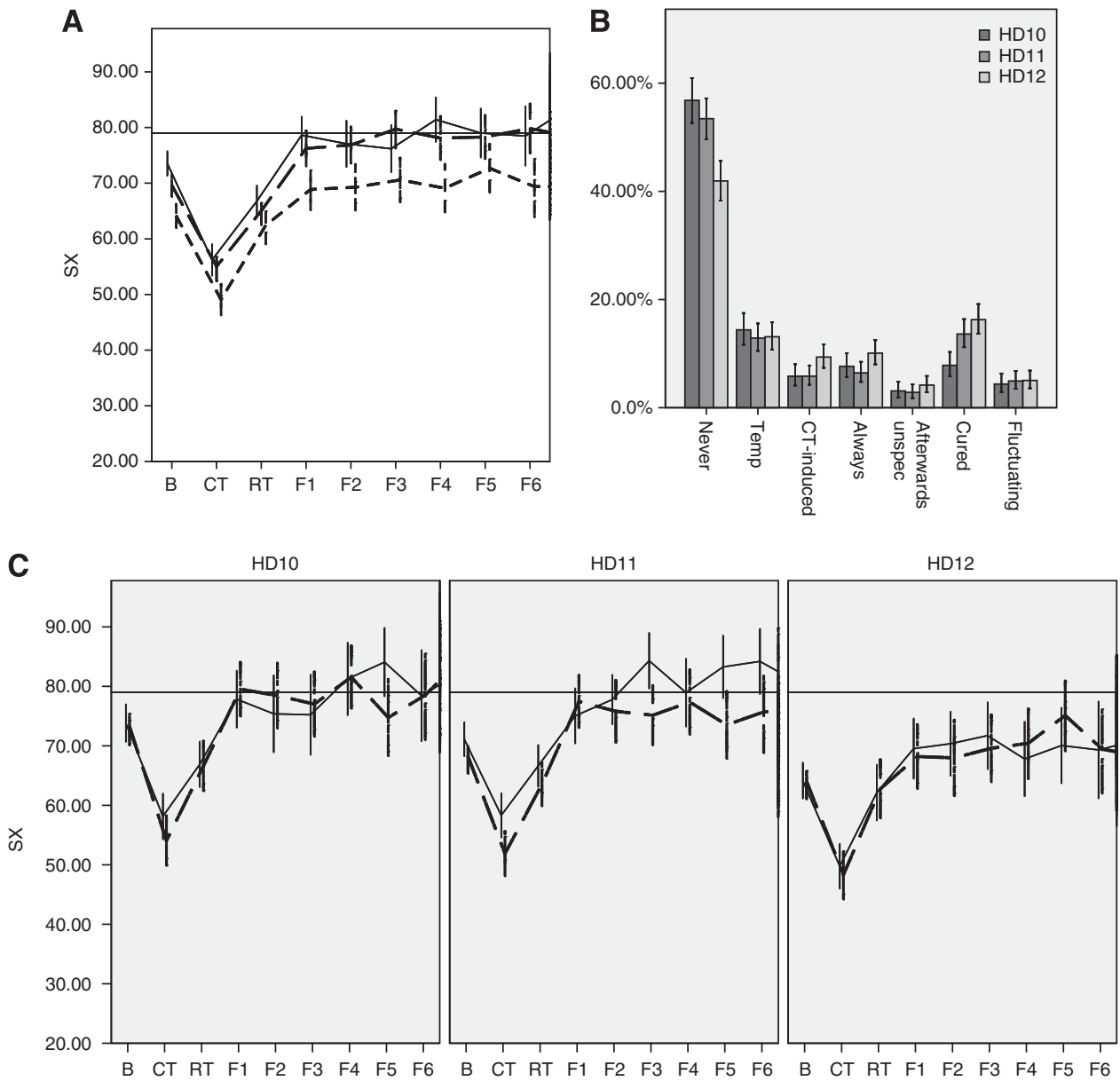

D
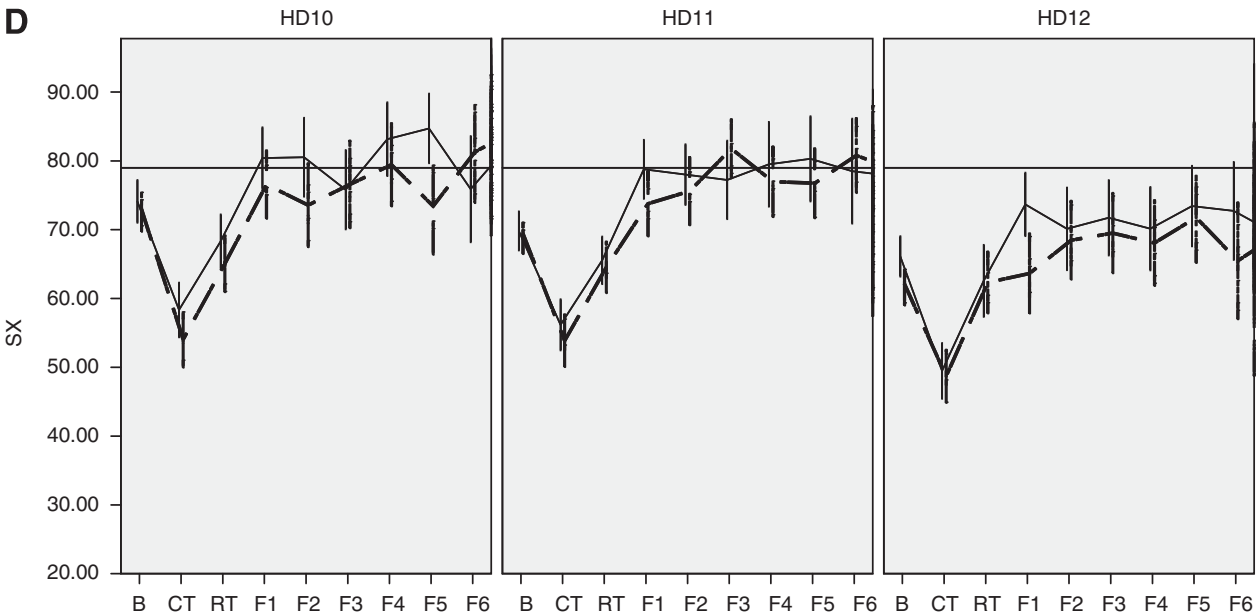

Figure 2. (A) Sexual functioning and disease stage (HD10-HD12); mean value and 95\% confidence interval (Cl); horizontal line: reference score of healthy controls (79); solid line HD10; long dashed line HD11; short dashed line HD12. (B) Relative frequencies of SX course types in HD10, HD11, and HD12 with 95\% CLs. (C) Sexual functioning and CT intensity in HD10-HD12; mean value and 95\% Cl; horizontal line: reference score of healthy controls; solid lines: lower intensity; dashed lines: higher intensity. (D) Sexual functioning and RT intensity (HD10-HD12); mean values and $95 \% \mathrm{Cl}$; controls $=0.79$; solid line: lower intensity; dashed line: higher intensity. 
Chemotherapy intensity. There were no statistically significant differences of SX between the treatment arms in HD10 and HD12. In contrast, in HD11, four cycles ABVD were associated with more favourable SX after therapy than four cycles of BEACOPP baseline (Figure 2C).

Radiotherapy intensity. There were no relevant differences of SX between the treatment arms with higher and lower RT intensity. However, there were slightly higher long-term SX scores for the patients with lower RT intensity in HD10 and HD12. This may reflect small but substantial advantages for these conditions, but they are not completely consistent, difficult to explain and clearly below the 10 point margin for clinical relevance (Figure 2D).

Age. Patients younger than 50 years had consistently higher levels of SX than older patients. These differences were most pronounced in early unfavourable and advanced stages during the follow-up period. While scores reached normal values in early stages for all age groups, a clinically relevant score difference was observed in the follow-up period for advanced-stage patients (Figure 3A).

Gender. Female patients had lower levels of SX throughout all stages compared with males. In advanced stages, lower SX scores compared with the reference line were similarly seen in women, as well as in men (Figure 3B).

Fatigue. Patients suffering from FA at baseline had lower SX scores than patients without FA symptoms. During follow-up, an improvement of SX was most pronounced in patients with FA. Furthermore, in early stages, levels close to normal scores were reached with and without FA at baseline (Figure 4A).

Social functions. Sexual functioning scores were significantly lower in patients with restricted SFs at baseline. Before therapy, score differences up to $<20$ points were observed. After therapy, in advanced stages, a clinically relevant score difference in patients with restricted SF compared with normal controls remained present (Figure 4B).

Sexual functioning and other quality of life domains. A multivariate SEM model of relations at baseline showed high correlations between all EORTC QLQ-C30 scales. Fatigue was negatively $(-0.39)$ and social functioning positively correlated with SX at baseline (0.41). Furthermore, the negative influences of higher age (beta $=-0.19$ ), advanced stages (beta $=-0.16$ ) and female gender (beta $=-0.09$ ) are already present in this multivariate analysis of baseline scores (Figure 5A).

Longitudinal model of SX, FA and SF. Fatigue and SF are known to be relevant for SX. Therefore, a longitudinal model for SX, FA, and SF at baseline and two follow-up times was estimated in multiple group comparisons of stage, gender, and age. As usual in path diagrams of SEM models, the variables in circles represent quantitative latent variables that were defined and measured via the observed variable scores in the respective time frame (measurement model not shown in Figure 5B). The variables at

A
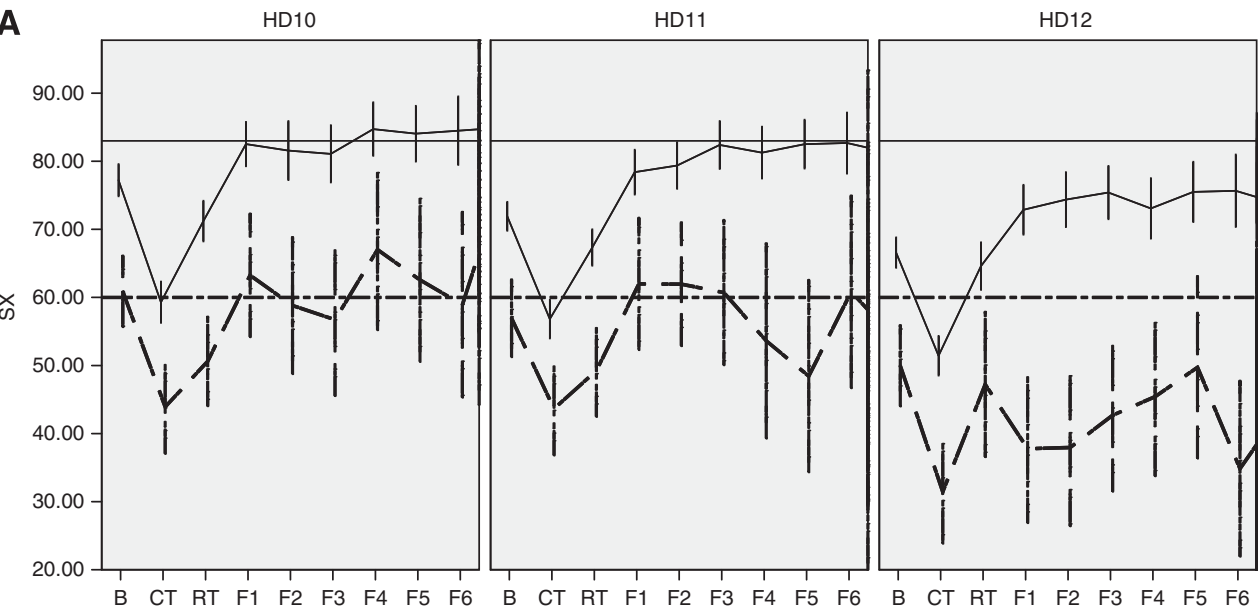

B

HD10

\begin{abstract}
HD11
\end{abstract}

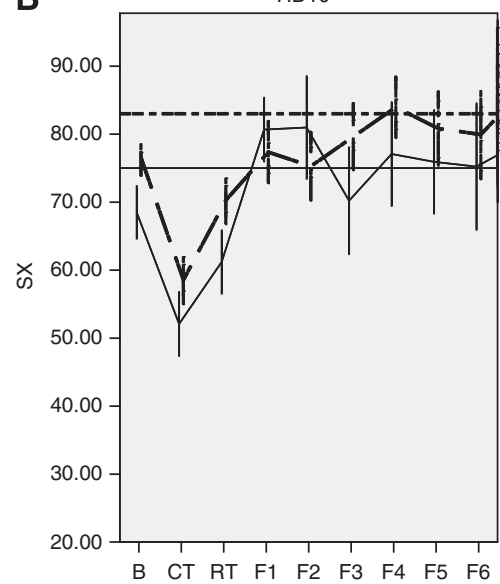

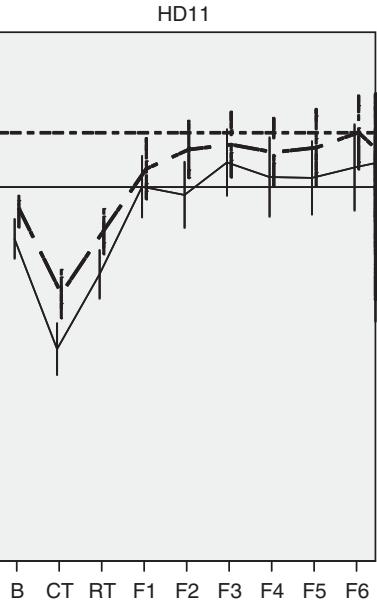

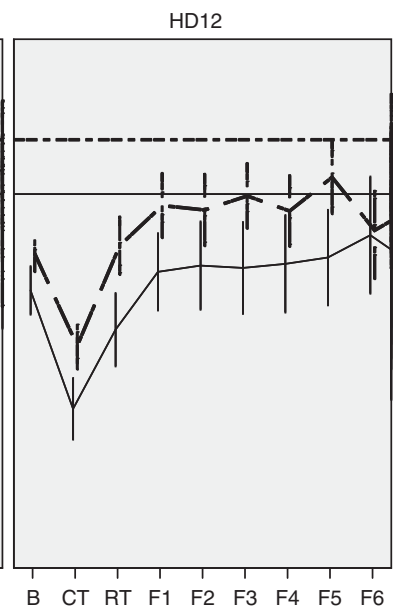

Figure 3. (A) Sexual functioning and age (HD10-HD12); mean value and $95 \%$ confidence interval (Cl); solid lines: $<50$ years (controls $=83$ ); dashed lines: $\geqslant 50$ years (controls $=60)$. (B) Sexual functioning and gender (HD10-HD12); mean value and 95\% Cl; solid lines: women (controls $=75$ ); dashed lines: men (controls $=83$ ). 
A
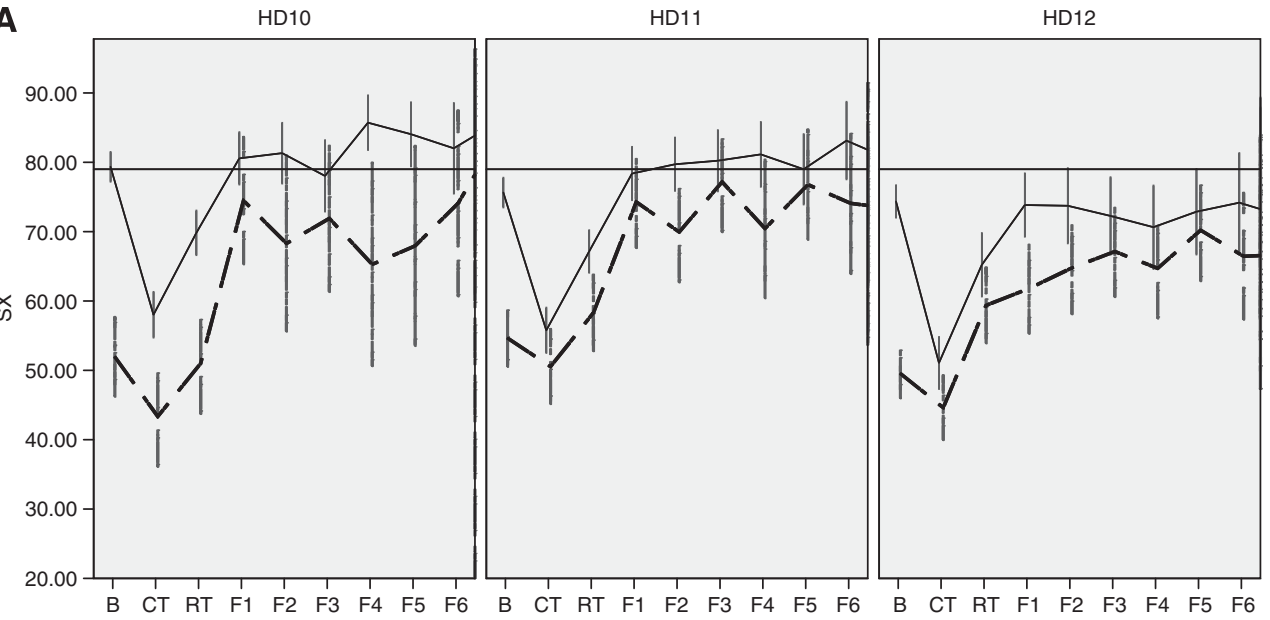

B
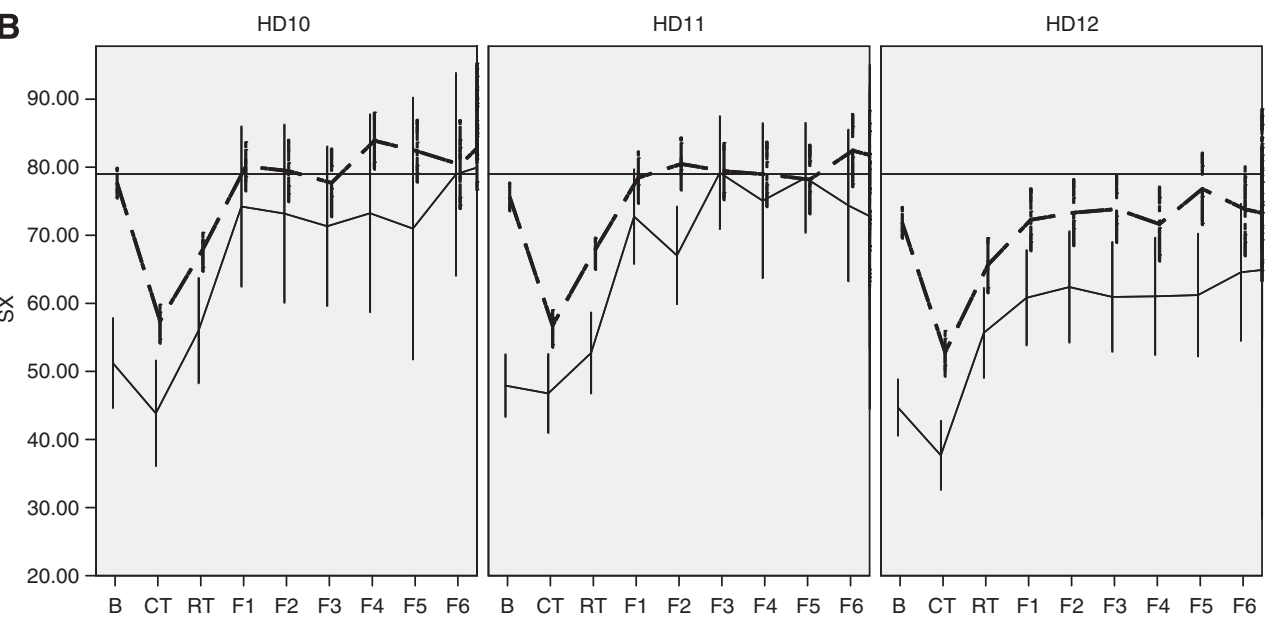

Figure 4. (A) Sexual functioning and FA (HD10-HD12); mean value and 95\% confidence interval (Cl); solid lines: without FA at baseline; dashed lines: with FA at baseline. (B) Sexual functioning and SFs (HD10-HD12); mean value and 95\% Cl; solid lines: restricted SF at baseline; dashed lines: normal SF at baseline.

baseline are depicted in squares as these were the simple observed scores of SX, FA and SF. Note that this model does not rely on our classification system of changes or any cutoffs for severity of impairment. It estimates relations between the measured quantitative variables and, therefore, can be used for sexual quality of life in general and any severity grade of impairment. With RMSEA $=0.015$ and CFI $=0.975$, the model shows excellent fit to the data and is a reasonable foundation for more detailed analyses and comparisons.

The estimates affirm that former scores of the variables are significant predictors of future states, whereby the high betas $(0.92-0.95)$ for the relationship between first and second follow-up indicate a high stability of SX, FA, and SF after 1 year. Baseline scores significantly predicted the 1-year scores, but prediction was clearly less precise (beta $=0.27$ to 0.33 ). At baseline, all analysed subgroups with one exception had significantly different SX, FA, and SF scores; only for FA at baseline, age made no significant difference. Advanced stages and female gender were associated with lower reported quality of life, older patients reported higher SF and lower SX. At first follow-up, older patients reported less improvement of their SX, FA, and SF scores compared with younger patients. Interestingly, at first follow-up, SF scores in early stages improved significantly more than in advanced stages, but FA and SX scores did not. At the second follow-up, no further score shifts were significant with exception of SX scores that increased in HD10 more than in HD12 (Figure 5B).

\section{DISCUSSION}

This is the first prospective study analysing SX in HL patients covering the initial diagnosis and up to 27 months of follow-up. The data set analysed included 3208 patients treated in the GHSG clinical trials HD10-12. The following major findings emerge from this analysis:

- Half of all patients analysed (50.1\%) did not report a severe impairment of SX. A benefit of therapy was found in advanced stages with more patients improving after therapy than suffering from CT-induced side effects on SX.

- After therapy, an improvement of SX compared with baseline was seen, especially in patients with poor baseline scores, except for those older than 50 years.

- Patients in early stages reached normal SX after therapy, whereas levels of patients in advanced stages improved but remained below the reference value.

- In HD11, the only trial comparing ABVD and BEACOPP, a small but significant difference of SX in favour of ABVD was detected. 

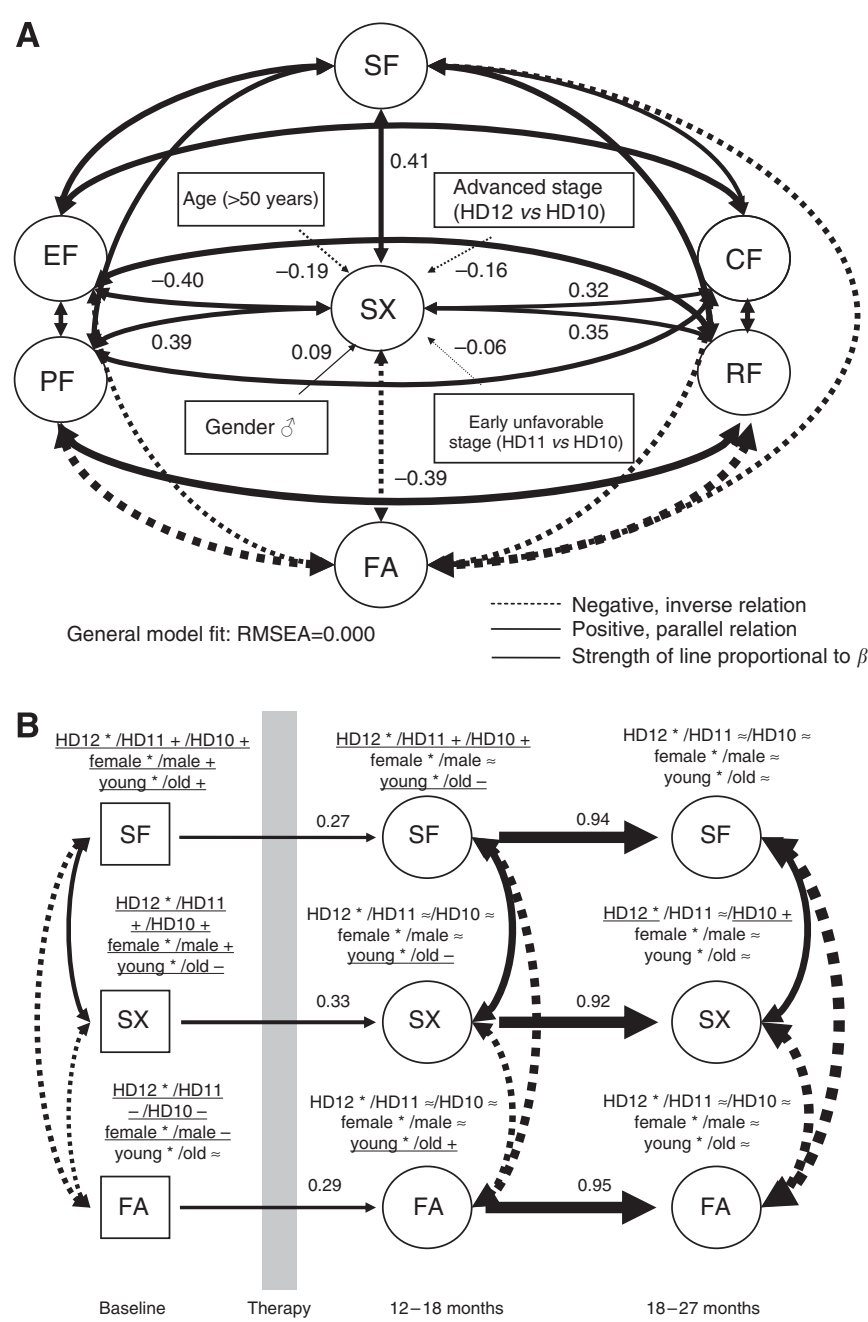

Figure 5. (A) Correlations of sexual functioning and QLQ-C30 scales at baseline: $C F=$ cognitive functions, $R F=$ role functions, $P F=$ physical functions, $E F=$ emotional functions. Additionally, the influence of age, gender, and stage is estimated with standardized path coefficients $\beta$. (B) Longitudinal model of SX, FA, and SF with subgroup comparisons for stage, gender and age (young: $<50$ years, old: $\geqslant 50$ years). Asterisks mark the reference category of subgroups, + positive differences to reference category, - negative differences to reference category, and $\approx$ a non-significant difference to reference category. Bold and underlined subgroups are significantly different $(P<01)$. Global model fit: RMSEA $=0.015, \mathrm{CFI}=0.975$, measurement model with $3 \times 6=18$-dependent variables omitted for clarity.

- In a structural equation model, FA was highly negative and SF highly positive correlated with SX. Negative influences of higher age, advanced-stage, and female gender were already seen in multivariate analysis of baseline scores. Looking at the development of SX over time, age $\geqslant 50$ years and advanced-stage further diminished the recovery of SX during follow-up. Sexual functioning scores from 12 to 18 months are highly predictive for SX scores up to 27 months.

Between seventy and eighty percent of patients were without persisting impairment of SX. As there are no established threshold levels for the evaluation of specific QoL dimensions, we choose a 50 -point cutoff for the discrimination between patients with or without SX impairment as this value is proposed as threshold level for clinical interventions (Klinkhammer-Schalke et al, 2008). By choosing this cutoff point, we only rely on serious impairments of SX whose relevance can hardly be denied. An additional limitation of our study is the lack of information on anamnestic relevant details and subcomponents of sexuality. Thus, we describe a very global indicator (SX) that hides many clinically important details of sexuality. The three items of the SX scale are not in widespread use although they are part of an EORTC study and fulfil basic psychometric requirements. A further limitation results from the substantial amount of missing data. Although we detected no serious bias with several analysis techniques and thorough investigation, distortion of results due to some sort of bias cannot be excluded completely for principal reasons. Principal reasons limit also conclusions from the longitudinal model. Although it fits the data very well $(\mathrm{RMSEA}=0.015)$, this is no proof of correctness or completeness: other models and further variables may do even better. To summarise, most of these limitations are typical and hardly avoidable for quality of life studies. To us, the most serious restriction is that we have no information on further details of sexuality, partnership, and related areas as this would directly support the development of effective interventions.

In a cohort study analysing SX in 465 long-term HL survivors and 205 sibling controls, sexual problems were commonly present in HL survivors, with $54.2 \%$ reporting decreased sexual activity and $41.1 \%$ reporting decreased sexual interest. No association with time since diagnosis, disease stage, or CT were detected (Recklitis et al, 2010). Compared with this study, the strength of our analysis is the fact that we had information on SX and patient characteristics before starting treatment. This enabled us to investigate possible correlation of these characteristics with SX independently of therapy - but not independently of HL stage. Thus, already before therapy there was a significant negative impact of higher disease stage, which is reduced but not completely vanished after therapy. Also, we observed some influence of CT on sexual quality of life. As the intensity of CT depends almost completely on the lymphoma stage at baseline, the large-scale impact of CT cannot be evaluated in our data. Focussing on the distinct risk groups, no differences were found for early favourable and advanced-stage patients. In these studies, other toxicities were reported to be clearly in favour of the less aggressive treatment arm (Engert et al, 2010). This indicates at least no major impact of CT intensity on the outcome of SX. However, in the HD11 trial (four ABVD vs four BEACOPP baseline) we found a significant difference in favour of ABVD. This difference might indicate a specific and negative impact of the BEACOPP regimen on SX. As compared with ABVD, even BEACOPP baseline contains high doses of alkylating agents. Alkylating agent based CT is known to induce gonadal toxicity (FranchiRezgui et al, 2003; Behringer et al, 2005; van der Kaaij et al, 2007; De Bruin et al, 2008; Sieniawski et al, 2008; Kiserud et al, 2009). Lower SX scores after therapy might be related to the gonadotoxicity of the treatment and consequently to low sex hormone levels (Greenfield et al, 2010),(Kiserud et al, 2009),(Howell et al, 2000). However, in a total of 273 advanced-stage HL survivors, the authors detected no statistically significant advantage in psychosexual function for patients treated with ABVD compared with patients treated with mechlorethamine, vincristine, procarbazine, prednisone (MOPP) or MOPP/ABVD(Kornblith et al, 1992a; Kornblith et al, 1992b) and a randomized testosterone replacement therapy in men with mild Leydig cell insufficiency detected no treatment effect on interest in sex and sexual activity (Howell et al, 2001).

The EORTC published data on quality of life after successful treatment of early-stage HL and used the same items for the assessment of sexual function as we did. Similar to our findings, SX improved with time. Furthermore, older age and female gender negatively influenced SX (Heutte et al, 2009). An age and gender effect was also observed in other trials analysing sexual function in patients after treatment for lymphoma (Huyghe et al, 2009; Kiserud et al, 2009). 
To conclude, sexual functions are of major concern in $\mathrm{HL}$ patients (van Tulder et al, 1994; Abrahamsen et al, 1998). However, in our analysis, half of all patients never suffered from a severe impairment of SX. Our findings demonstrate that SX at baseline are negatively influenced by a higher disease stage, i.e., tumour burden. Fortunately, during follow-up, decreased sexual quality of life is usually improving. Overall, young patients in early stages can expect normalisation, whereas patients in advanced stages and patients older than 50 years have an increased risk for long-term deficits. Our analysis does not support the hypothesis that a single causal factor may explain long-term impairment of SX to high extent. In contrast, the complexity of different factors contributing to healthy SX indicates a demand of a patient-specific view and individual diagnostics.

\section{CONCLUSIONS}

First, to improve the communication about sexual problems between health professionals and patients. Before and after therapy, professionals should inform patients about their individual likelihood of a severe impairment of SX, as well as the expected improvement of sexual quality of life during follow-up. Patients want an open communication about their individual sexuality. However, the understanding of sexuality of most health professionals does not match patients' expectations. Additionally, there is rarely time and some feel embarrassed to discuss these issues (Hordern and Street, 2007).

Second, to further develop targeted and efficacious interventions for sexual deficits in lymphoma survivors as soon as possible. Knowing that an association between sexual dysfunction and depression has been reported, delaying such an intervention in our survivors may result in unnecessary further psychological consequences (Arden-Close et al, 2011).

\section{ACKNOWLEDGEMENTS}

This work was supported by the Deutsche Krebshilfe, the Bundesministerium für Bildung und Forschung (BMBF), and the Kompetenznetz Maligne Lymphome.

\section{REFERENCES}

Aaronson NK, Ahmedzai S, Bergman B, Bullinger M, Cull A, Duez NJ, Filiberti A, Flechtner H, Fleishman SB, de Haes JC (1993) The European Organization for Research and Treatment of Cancer QLQ-C30: a quality-of-life instrument for use in international clinical trials in oncology. J Natl Cancer Inst 85(5): 365-376.

Abrahamsen A, Loge J, Hannisdal E, Holte H, Kvaloy S (1998) Socio-medical situation for long-term survivors of Hodgkin's disease: a survey of 459 patients treated at one institution. Eur J Cancer 34(12): p1865-p1870.

Arden-Close E, Eiser C, Pacey A (2011) Sexual Functioning in male survivors of lymphoma: a systematic review. J Sex Med 8(7): 1833-1840.

Behringer K, Breuer K, Reineke T, May M, Nogova L, Klimm B, Schmitz T, Wildt L, Diehl V, Engert A (2005) Secondary amenorrhea after Hodgkin's lymphoma is influenced by age at treatment, stage of disease, chemotherapy regimen, and the use of oral contraceptives during therapy: a report from the German Hodgkin's Lymphoma Study Group. J Clin Oncol 23(30): 7555-7564.

Bober SL, Recklitis CJ, Campbell EG, Park ER, Kutner JS, Najita JS, Diller L (2009) Caring for cancer survivors: a survey of primary care physicians. Cancer 115(18 Suppl): 4409-4418.

Borchmann P, Haverkamp H, Diehl V, Cerny T, Markova J, Ho AD, Eich HT, Mueller-Hermelink HK, Kanz L, Greil R, Rank A, Paulus U, Smardova L, Huber C, Dorken B, Nerl C, Krause SW, Mueller RP, Fuchs M, Engert A
(2011) Eight cycles of escalated-dose BEACOPP Compared with four cycles of escalated-dose BEACOPP followed by four cycles of baselinedose BEACOPP with or without radiotherapy in patients with advancedstage Hodgkin's Lymphoma: final analysis of the hd12 trial of the German Hodgkin Study Group. J Clin Oncol 29(32): 4234-4242.

Cocks K, King MT, Velikova G, Fayers PM, Brown JM (2008) Quality, interpretation and presentation of European Organisation for Research and Treatment of Cancer quality of life questionnaire core 30 data in randomised controlled trials. Eur J Cancer 44(13): 1793-1798.

De Bruin ML, Huisbrink J, Hauptmann M, Kuenen MA, Ouwens GM, van't Veer MB, Aleman BM, van Leeuwen FE (2008) Treatment-related risk factors for premature menopause following Hodgkin lymphoma. Blood 111(1): 101-108.

Eich HT, Diehl V, Gorgen H, Pabst T, Markova J, Debus J, Ho A, Dorken B, Rank A, Grosu AL, Wiegel T, Karstens JH, Greil R, Willich N, Schmidberger H, Dohner H, Borchmann P, Muller-Hermelink HK, Muller RP, Engert A (2010) Intensified chemotherapy and dose-reduced involved-field radiotherapy in patients with early unfavorable Hodgkin's lymphoma: final analysis of the German Hodgkin Study Group HD11 trial. J Clin Oncol 28(27): 4199-4206.

Engert A, Diehl V, Franklin J, Lohri A, Dorken B, Ludwig WD, Koch P, Hanel M, Pfreundschuh M, Wilhelm M, Trumper L, Aulitzky WE, Bentz M, Rummel M, Sezer O, Muller-Hermelink HK, Hasenclever D, Loffler M (2009) Escalated-dose BEACOPP in the treatment of patients with advanced-stage Hodgkin's lymphoma: 10 years of follow-up of the GHSG HD9 study. J Clin Oncol 27(27): 4548-4554.

Engert A, Plutschow A, Eich HT, Lohri A, Dorken B, Borchmann P, Berger B, Greil R, Willborn KC, Wilhelm M, Debus J, Eble MJ, Sokler M, Ho A, Rank A, Ganser A, Trumper L, Bokemeyer C, Kirchner H, Schubert J, Kral Z, Fuchs M, Muller-Hermelink HK, Mulle RP, Diehl V (2010) Reduced treatment intensity in patients with early-stage Hodgkin's lymphoma. N Engl J Med 363(7): 640-652.

Fegg MJ, Gerl A, Vollmer TC, Gruber U, Jost C, Meiler S, Hiddemann W (2003) Subjective quality of life and sexual functioning after germ-cell tumour therapy. Br J Cancer 89(12): 2202-2206.

Flechtner H, Ruffer J, Henry-Amar M, Mellink W, Sieber M, Ferme C, Eghbali H, Josting A, Diehl V (1998) Quality of life assessment in Hodgkin's disease: a new comprehensive approach. First experiences from the EORTC/GELA and GHSG trials. EORTC Lymphoma Cooperative Group. Groupe D'Etude des Lymphomes de L'Adulte and German Hodgkin Study Group. Ann Oncol 9(Suppl 5): S147-S154.

Franchi-Rezgui P, Rousselot P, Espie M, Briere J, Pierre Marolleau J, Gisselbrecht C, Brice P (2003) Fertility in young women after chemotherapy with alkylating agents for Hodgkin and non-Hodgkin lymphomas. Hematol J 4(2): 116-120.

Greenfield DM, Walters SJ, Coleman RE, Hancock BW, Snowden JA, Shalet SM, DeRogatis LR, Ross RJ (2010) Quality of life, self-esteem, fatigue, and sexual function in young men after cancer: a controlled cross-sectional study. Cancer 116(6): 1592-1601.

Heutte N, Flechtner HH, Mounier N, Mellink WA, Meerwaldt JH, Eghbali H, van't Veer MB, Noordijk EM, Kluin-Nelemans JC, Lampka E, Thomas J, Lugtenburg PJ, Viterbo L, Carde P, Hagenbeek A, van der Maazen RW, Smit WG, Brice P, van Marwijk Kooy M, Baars JW, Poortmans P, Tirelli U, Leeksma OC, Tomsic R, Feugier P, Salles G, Gabarre J, Kersten MJ, Van Den Neste E, Creemers GJ, Gaillard I, Meijnders P, Tertian G, Reman O, Muller HP, Troncy J, Blanc M, Schroyens W, Voogt PJ, Wijermans P, Rieux C, Ferme C, Henry-Amar M (2009) Quality of life after successful treatment of early-stage Hodgkin's lymphoma: 10-year follow-up of the EORTC-GELA H8 randomised controlled trial. Lancet Oncol 10(12): $1160-1170$.

Hordern AJ, Street AF (2007) Communicating about patient sexuality and intimacy after cancer: mismatched expectations and unmet needs. Med J Aust 186(5): 224-227.

Howell SJ, Radford JA, Adams JE, Smets EM, Warburton R, Shalet SM (2001) Randomized placebo-controlled trial of testosterone replacement in men with mild Leydig cell insufficiency following cytotoxic chemotherapy. Clin Endocrinol (Oxf) 55(3): 315-324.

Howell SJ, Radford JA, Smets EM, Shalet SM (2000) Fatigue, sexual function and mood following treatment for haematological malignancy: the impact of mild Leydig cell dysfunction. Br J Cancer 82(4): 789-793.

Huyghe E, Sui D, Odensky E, Schover LR (2009) Needs assessment survey to justify establishing a reproductive health clinic at a comprehensive cancer center. J Sex Med 6(1): 149-163. 
Kiserud CE, Fossa A, Bjoro T, Holte H, Cvancarova M, Fossa SD (2009) Gonadal function in male patients after treatment for malignant lymphomas, with emphasis on chemotherapy. Br J Cancer 100(3): 455-463.

Kiserud CE, Schover LR, Dahl AA, Fossa A, Bjoro T, Loge JH, Holte H, Yuan Y, Fossa SD (2009) Do male lymphoma survivors have impaired sexual function? J Clin Oncol 27(35): 6019-6026.

Klinkhammer-Schalke M, Koller M, Ehret C, Steinger B, Ernst B, Wyatt JC, Hofstadter F, Lorenz W (2008) Implementing a system of quality-of-life diagnosis and therapy for breast cancer patients: results of an exploratory trial as a prerequisite for a subsequent RCT. Br J Cancer 99(3): 415-422.

Kornblith A, Anderson J, Cella D, Tross S, Zuckerman E, Cherin E, Henderson E, Canellos G, Kosty M, Cooper M (1992a) Comparison of psychosocial adaptation and sexual function of survivors of advanced Hodgkin disease treated by MOPP, ABVD, or MOPP alternating with ABVD. Cancer 70(10): p2508-p2516.

Kornblith A, Anderson J, Cella D, Tross S, Zuckerman E, Cherin E, Henderson E, Weiss R, Cooper M, Silver R (1992b) Hodgkin disease survivors at increased risk for problems in psychosocial adaptation. The Cancer and Leukemia Group B. Cancer 70(8): p2214-p2224.

Mercadante S, Vitrano V, Catania V (2010) Sexual issues in early and late stage cancer: a review. Support Care Cancer 18(6): 659-665.

Muthén LK, Muthén BO (1998-2007) Mplus User's Guide. Fifth Edn. Muthén \& Muthén: Los Angeles, CA.

Osoba D, Bezjak A, Brundage M, Zee B, Tu D, Pater J (2005) Analysis and interpretation of health-related quality-of-life data from clinical trials: basic approach of The National Cancer Institute of Canada Clinical Trials Group. Eur J Cancer 41(2): 280-287.

Osoba D, Rodrigues G, Myles J, Zee B, Pater J (1998) Interpreting the significance of changes in health-related quality-of-life scores. J Clin Oncol 16(1): 139-144.

Park ER, Bober SL, Campbell EG, Recklitis CJ, Kutner JS, Diller L (2009) General internist communication about sexual function with cancer survivors. J Gen Intern Med 24(Suppl 2): S407-S411.

Quinn GP, Vadaparampil ST, Gwede CK, Miree C, King LM, Clayton HB, Wilson C, Munster P (2007) Discussion of fertility preservation with newly diagnosed patients: oncologists' views. J Cancer Surviv 1(2): 146-155.

Recklitis CJ, Sanchez Varela V, Ng A, Mauch P, Bober S (2010) Sexual functioning in long-term survivors of Hodgkin's lymphoma. Psychooncology 19(11): 1229-1233.
Ruffer JU, Flechtner H, Tralls P, Josting A, Sieber M, Lathan B, Diehl V (2003) Fatigue in long-term survivors of Hodgkin's lymphoma; a report from the German Hodgkin Lymphoma Study Group (GHSG). Eur J Cancer 39(15): 2179-2186.

Sadovsky R, Basson R, Krychman M, Morales AM, Schover L, Wang R, Incrocci L (2010) Cancer and sexual problems. J Sex Med 7(1 Pt 2): 349-373.

Schover LR (2005) Sexuality and fertility after cancer. Hematology Am Soc Hematol Educ Program 2005: 523-527.

Sieniawski M, Reineke T, Josting A, Nogova L, Behringer K, Halbsguth T, Fuchs M, Diehl V, Engert A (2008) Assessment of male fertility in patients with Hodgkin's lymphoma treated in the German Hodgkin Study Group (GHSG) clinical trials. Ann Oncol 19(10): 1795-1801.

van der Kaaij MA, Heutte N, Le Stang N, Raemaekers JM, Simons AH, Carde P, Noordijk EM, Ferme C, Thomas J, Eghbali H, Kluin-Nelemans HC, Henry-Amar M (2007) Gonadal function in males after chemotherapy for early-stage Hodgkin's lymphoma treated in four subsequent trials by the European Organisation for Research and Treatment of Cancer: EORTC Lymphoma Group and the Groupe d'Etude des Lymphomes de l'Adulte. J Clin Oncol 25(19): 2825-2832.

van Tulder MW, Aaronson NK, Bruning PF (1994) The quality of life of longterm survivors of Hodgkin's disease. Ann Oncol 5(2): 153-158.

Webber K, Mok K, Bennett B, Lloyd AR, Friedlander M, Juraskova I, Goldstein D (2011) If $i$ am in the mood, $i$ enjoy it: an exploration of cancer-related fatigue and sexual functioning in women with breast cancer. Oncologist 16(9): 1333-1344.

Weissbach L, Bussar-Maatz R, Flechtner H, Pichlmeier U, Hartmann M, Keller L (2000) RPLND or primary chemotherapy in clinical stage IIA/B nonseminomatous germ cell tumors? Results of a prospective multicenter trial including quality of life assessment. Eur Urol 37(5): 582-594.

Zebrack BJ, Mills J, Weitzman TS (2007) Health and supportive care needs of young adult cancer patients and survivors. J Cancer Surviv 1(2): $137-145$.

This work is published under the standard license to publish agreement. After 12 months the work will become freely available and the license terms will switch to a Creative Commons AttributionNonCommercial-Share Alike 3.0 Unported License. 